\section{The Presentation of Self in Everyday Life: biografia de um livro}

\author{
The Presentation of \\ Self in Everyday Life: \\ biography of a book
}

\section{Everardo Duarte Nunes ${ }^{i}$}

i Departamento de Saúde Coletiva/Faculdade de Ciências Médicas/ Universidade Estadual de Campinas. Campinas - São Paulo - Brasil

orcid.org/0000-0002-2285-7473

evernunes@uol.com.br
NUNES, Everardo Duarte. The Presentation of Self in Everyday Life: biografia de um livro. História, Ciências, Saúde - Manguinhos, Rio de Janeiro, v.28, n.3, jul.-set. 2021, p.761-774.

Resumo

Na marca dos 60 anos de sua publicação, este artigo reconstrói a biografia do livro The presentation of self in everyday life, de Erving Goffman, de 1959. Utiliza-se, de forma adaptada, a perspectiva de Robert Darnton, original e revisitada pelo autor em seus estudos sobre a história dos livros. Além desse referencial, o artigo faz uso de textos originais de Goffman, da tradução brasileira, de estudos bibliográficos, artigos críticos, resenhas, coletâneas, e de entrevistas e informações que fazem parte do Erving Goffman Archives. Na análise da obra, procurase acompanhar a trajetória do autor, enfatizando a importância e o impacto do texto, com dados quantitativos e qualitativos, cuja importância estende-se além da academia.

Palavras-chave: Erving Goffman (19221982); história do livro; bibliografia; história; biografia do livro.

\section{Abstract}

Sixty years after Erving Goffman's book The Presentation of Self In Everyday Life was published (1959), this article reconstructs its biography by adapting the perspective of Robert Darnton (the original, as well as the revisited one on the history of books). Original texts by Goffman in Brazilian translations are used, along with bibliographical studies, critical articles, reviews, collections, and interviews and information that are part of the Erving Goffman Archives. The goal is to follow this author's trajectory, emphasizing the importance and impact of his text, with quantitative and qualitative data that extend beyond academia in terms of importance.

Keywords: Erving Goffman (1922-1982); history of the book; bibliography; history; biography of the book. 
A leitura continua a ser a etapa mais difícil de estudar no circuito seguido pelos livros (Darnton, 1982, p.74).

Este artigo trata da biografia de um livro que está completando 60 anos: The presentation of self in everyday life, de Erving Goffman (1922-1982), publicado em 1959, versão revisada e ampliada da monografia datada de 1956 (Goffman, 1956, 1959). A abordagem do tema toma como referência principal as ideias de Robert Darnton (1939-), historiador da cultura, especialista em história da França do século XVIII e da história dos livros, ex-professor e bibliotecário da Harvard University Library. Utiliza o clássico estudo de 1982 e sua versão revisitada, de 2007, mais a coletânea de seus textos de 2009, quando dialoga com Adams e Barker (1993), e a proposta de um novo modelo para o estudo do livro desses autores (Darnton, 1982, 2007).

Considero que escrever a biografia de um livro é adentrar "uma importante nova disciplina"1 - a história dos livros, que, segundo Darnton (1982, p.65),

surgiu da convergência de várias disciplinas em um conjunto comum de problemas, todos eles relacionados ao processo de comunicação. ... Afinal, a história da história dos livros não começou ontem. Ela remonta à erudição da Renascença, se não além, e começou de fato durante o século XIX, quando o estudo dos livros como objetos materiais levou ao surgimento da bibliografia analítica na Inglaterra.

Darnton (1982, p.68) adianta que "A história dos livros se tornou tão repleta de disciplinas auxiliares, que não se pode mais ver seus contornos gerais", fazendo-se necessário ver o assunto como um todo. Ao desenvolver o que denomina "círculo da vida" de um livro, estabelece um circuito de comunicações que se estende do autor ao leitor, trabalhando as relações autor/ leitor/revisores/críticos, dando-lhe "sentido geral de empresa literária". O autor afirma que, se a "conjuntura econômica e social" é um destaque importante, devem também incluir os "subconjuntos que a ela se associam: as "influências intelectuais e a publicidade", assim como as "sanções políticas e legais". Todo o processo é sintetizado em um modelo gráfico - o circuito de comunicações - interconectado com o circuito entre autor $\leftrightarrow$ editor $\rightarrow$ impressores $\rightarrow$ remetentes $\rightarrow$ livreiros $\rightarrow$ leitores, retornando ao autor $\leftrightarrow$ editor.

Darnton (2007, p.502, 504) reconhece que o "documento bibliográfico", expressão usada por Adams e Barker (1993), e "sua proposta de ampliar o escopo do meu diagrama, torna-o mais adaptável às condições que prevaleciam após as primeiras décadas do século XIX". Nesse novo diagrama, eles distinguem cinco eventos: publicação, manufatura, distribuição, recepção e sobrevivência, mas pouco acresentam ao esquema anterior, a não ser pelo evento sobrevivência.

Considerando que não se pode perder a perspectiva do "autor", este trabalho apoia-se nas noções desenvolvidas pelo sociólogo Dmitri N. Shalin (2009), codiretor da International Biography Initiative, Erving Goffman Archives (EGA), denominadas "bios sociologicus". Segundo Shalin (2014, p.26):

A vida de Goffman é um excelente exemplo de bios-sociologicus - uma vida dedicada à ciência da sociedade, sem divisão nítida entre Goffman, o estudioso, e Goffman, o homem. Erving era um observador participante par excellence, constantemente explorando, experimentando, testando convenções sociais, traçando os limites da ordem da interação e irritando as pessoas que o rodeavam nesse processo. 


\section{E destaca um aspecto importante ao assinalar que Goffman}

baseou-se em sua própria experiência para entender as estratégias de auto-apresentação, o custo emocional do fracasso, as consequências insidiosas da estigmatização, os códigos da desigualdade de gênero e os trabalhos íntimos e filamentos da ordem da interação. Mas a confiança na experiência pessoal também influenciou sua percepção, distorceu suas generalizações e, em alguns casos, afetou a privacidade das pessoas pesquisadas (Shalin, 2014, p.27).

Shalin (2014, p.27) assinala também que "devemos lembrar que essas práticas tinham um significado diferente na época em que nenhum escrutínio do IRB (Institutional Review Board) governava o trabalho etnográfico, os costumes sociais eram tolerantes ao assédio moral e a opinião pública apoiava o sexismo e a misoginia". Considera, ainda, que, "ao colocar a vida e o trabalho de Goffman em seu contexto histórico, podemos aprender muito sobre a América de classe média em que ele viveu e que ele se esforçou para entender" (p.28).

Com esse trabalho, tendo como base o EGA, Shalin oferece uma das mais completas revisões da interface "vida e obra", o que o torna a principal referência em estudos biobibliográficos sobre Goffman. Portanto, citá-lo novamente é esclarecedor.

As bionarrativas não apenas nos instruem sobre seu objeto, mas iluminam a agenda e as convenções culturais do intérprete. Alguns intérpretes encontraram a chave da imaginação sociológica de Goffman em suas raízes culturais, outros vincularam suas ideias teóricas às suas tendências somático-afetivas, outros consideraram as orientações políticas e as sensibilidades existenciais desse sociólogo como a pedra de toque de sua criatividade pessoal e acadêmica (Shalin, 2014, p.31).

Com cautela, porém, escreve: "Claramente, o corpus de Goffman se sustenta por si próprio e deve ser julgado independentemente das interfaces entre os compromissos privados e de pesquisa desse pesquisador. E, no entanto, a linha de pesquisa proposta oferece um caminho frutífero para pesquisas que iluminam o papel vital que os recursos biográficos desempenham na imaginação sociológica" (Shalin, 2014, p.34). Considerandose que tanto Darnton como Shalin não apresentam conceitualmente a noção de autor e obra, acrescentou-se ao conceitual do trabalho o desenvolvimento dado por Foucault (1996) a essa questão.

As observações anteriores assinalam o encaminhamento metodológico deste trabalho. Ele se inclui no que se denomina pesquisa bibliográfica, associada à pesquisa biográfica. Entende-se por pesquisa bibliográfica, de forma bastante simplificada, "uma modalidade de estudo e análise de documentos de domínio científico tais como livros, periódicos, enciclopédias, ensaios críticos, dicionários e artigos científicos" (Oliveira, 2009, p.69). Neste trabalho, essa perspectiva se amplia com as contribuições teóricas e metodológicas de Shalin. As principais fontes documentais são: Goffman (1953, 1956, 1959), a tradução brasileira (Goffman, 1995); os estudos bibliográficos (Malufe, 1992; Smith, 1989, 1999; Carlin, 2004a, 2004b); artigos críticos, resenhas, entrevistas e informações que fazem parte do EGA; artigos biobibliográficos (Fine, Manning, Smith, 2000; Shalin, 2014) e a coletânea, em quatro volumes, organizada por Fine, Smith (2000). 


\section{Goffman: de Chicago para Shetland}

Em dezembro de 1949, Erving Goffman deixou Edimburgo e viajou para Unst, a mais setentrional das ilhas britânicas habitadas, pertencente ao arquipélago de Shetland (Escócia) - "no final da Grã-Bretanha".

Poucos meses antes, depois de concluído seu mestrado na Universidade de Chicago, Goffman havia sido indicado por seu tutor de mestrado, e agora de doutorado, W. Lloyd Warner (1898-1970), para a Universidade de Edinburgo, "que estava em processo de criação de um departamento de antropologia social" (Shalin, 2014, p.10). Lá permaneceu pouco tempo e viajou para Unst. Hospedou-se, inicialmente, no único hotel (Springfield, aberto em 1939), da vila de Baltasound, na costa leste da ilha, com cerca de trezentos habitantes.

Winkin (1988, p.67), que visitou a ilha e esteve em Baltasound em 1988, relata a entrevista com a proprietária do hotel, que havia conhecido Goffman: "Ele tinha o suficiente para pagar por seu quarto. Então ele ficou dois meses no Springfield Hotel, antes de se mudar para uma pequena cabana (casa de campo) a cem metros de distância". A entrevistada afirma que ele chegou "repentinamente ... [com] muitos bolsos de sua jaqueta militar cáqui e suas perneiras atadas ao joelho".

Goffman permaneceu em Baltasound de dezembro de 1949 a maio de 1951, quando deu por concluído seu trabalho de campo sobre a comunidade - que passou a denominar "Dixon" - e seus habitantes - "Berganders"-, que, segundo ele, "formam uma sociedade para si próprios" (Goffman, 1953, p.13).

\section{Breve biografia}

Quando chegou às ilhas Shetland, Goffman havia completado 27 anos. Filho de imigrantes judeus soviéticos (ucranianos), seus pais, Max Goffman (1890-1954) e Anne (Averbach) Goffman (1899-1989), chegaram ao Canadá (Winnipeg, Manitoba) no início do século XX, época em que o país recebeu cerca de 120 mil imigrantes judeus.

Erving Manual Goffman nasceu em Mannville (Alberta), Canadá, em 11 de julho de 1922; sua irmã, Florence, dois anos mais velha, nasceu em 1919 e seguiu a carreira artística, com marcante presença em televisão e cinema - faleceu em 2011. Max tornou-se um lojista de produtos agrícolas em Mannville, de 1915 a 1926, em uma comunidade majoritariamente de cristãos, o que certamente criou distâncias culturais, religiosas e de classe. Em 1926, Max abriu uma loja de roupas em Dauphin (Manitoba), e, em 1937, comprou uma casa para a família em Winnipeg, mas continou com a loja em Dauphin, que vendeu em 1950. Em 1952, Max e Anne mudaram-se para a Califórnia (EUA).

Goffman continuaria a tradição familiar de mudar de lugares, mas incluindo também instituições de ensino. Cursou o ensino médio (ciências e matemática) em Dauphin, de 1937 a 1939, no St. John's Technical High School. Em 1939, matriculou-se na Universidade de Manitoba (Winnipeg), onde estudou química. Durante seus três anos de graduação em Winnipeg, "seus interesses acadêmicos se modificaram gradualmente para as ciências sociais" (Smith, 2006, p.8). Em 1943, mudou-se para Ottawa, onde trabalhou no National Film Board of Canada. Data dessa época o contato com duas pessoas que se tornariam 
importantes em sua vida pessoal e acadêmica: Elizabeth Bott (1924-2016), que se tornaria destacada antropóloga e psicanalista, e Dennis Hume Wrong (1923-2018), sociólogo que foi a grande influência inicial para Goffman retomar os estudos na área de sociologia na Universidade de Toronto, onde concluiu a graduação em sociologia e antropologia em 1945, quando ingressou no mestrado na Universidade de Chicago, concluído em 1949. Em julho de 1952, casou-se com Angelica Schuyler Choate ("Sky" para os íntimos), de uma família protestante da alta sociedade de Boston. Ela concluiu o bacharelado em psicologia e, em 1950, defendeu seu mestrado sobre as características das mulheres da classe alta de sua cidade. Em 1953, Goffman concluiu o doutorado na Universidade de Chicago, ano em que nasceu seu filho Thomas Edward Goffman. Thomas formou-se em medicina, realizando atividades como profissional, pesquisador e docente em rádio-oncologia. Faleceu em 2010.

De 1954 a 1957, Goffman realizou pesquisas junto ao Laboratory of Socioenvironmental Studies, do National Institute for Mental Health (NIMH), em dois projetos: um breve estudo de duas enfermarias psiquiátricas do NIMH (em Besthesda e Maryland), e um ano de observação participante no St. Elizabeth's Hospital (em Washington, DC).

Em 1958, aceitou o convite de Herbert Blumer (1900-1987) para ser professor assistente visitante de psicologia social no Departamento de Sociologia da Universidade da Califórnia (Berkeley), do qual se tornaria professor associado em 1959 e professor em tempo integral em 1962. Em dezembro de 1960, solicitou licença não remunerada (nove meses) para permanercer em Las Vegas, a fim de treinar para jogar, apostar e pesquisar sobre jogos de azar. Sobre o tema, Goffman produziu um artigo em 1967, mas ele e a família foram "barrados dos cassinos de Nevada", assunto que permanece ainda sem explicações (Shalin, 2014, p.16, 17).

Estava lecionando em Berkeley em 1964 quando sua esposa, Angelica, suicidou-se. Segundo Fine, Manning e Smith (2000, p.XII), ela apresentava "graves problemas de saúde mental". Os autores apontam que "um paralelo pode existir entre os interesses acadêmicos de Goffman em saúde mental e as observações pessoais em seu lar", que se expressariam em seu ensaio "The insanity place" (Goffman, 1969), "indiscutivelmente autobiográfico".

Em 1966, cumpriu um ano sabático no Harvard Center for International Affairs; em 1968, renunciou ao cargo em Berkeley e aceitou a cátedra Benjamin Franklin em sociologia e antropologia na Universidade da Pensilvânia, com um salário de US\$30.000 anuais.

Em 1981, casa-se com Gillian Sankoff (1943-), no ano seguinte, nasce sua filha, Alice Goffman, que seguiria a carreira em sociologia, doutorando-se em 2010 pela Universidade de Princeton. Em 1981, Goffman foi eleito o $73^{\circ}$ Presidente da American Sociological Association, não tendo apresentado seu discurso presidencial, pois se encontrava hospitalizado, vítima de um câncer de estômago. Goffman faleceu em 19 de novembro de 1982, na Filadélfia, Pensilvânia. Sua apresentação presidencial, intitulada "The interaction order", seria publicada no ano seguinte (Goffman, 1983).

\section{Da tese ao livro}

A tese Communication conduct in an island community (Goffman, 1953), com 368 páginas, não publicada, foi o resultado do que ele havia denominado trabalho épico. A abertura da tese 
é uma longa epígrafe de Georg Simmel (1858-1918), que, entre outros pontos, aponta uma questão que seria fundamental na obra de Goffman, a existência de "um número imensurável de formas menos visíveis de relacionamento e tipos de interação" (Simmel, c.1950, p.9-10).

As palavras iniciais de Goffman (1953, p.1) em sua tese são: "Este é um relato sobre o estudo da interação conversacional. ... O objetivo da pesquisa é isolar e registrar práticas recorrentes daquilo que é usualmente chamado de interação face a face". Análises apontam que "a tese foi uma mistura de observações e classificações: parte estudo de caso, parte teoria geral. Considerado trabalho precursor de toda a sua obra, também foi desconcertante para seus examinadores, que esperavam um estudo comunitário tradicional" (Manning, 2005, p.334). Acrescente-se que Goffman evitou o uso de estatísticas e tipologias convencionais de estratificação, fazendo uso de métodos observacionais.

A banca foi extremamente crítica no julgamento da tese, incluindo o diretor da tese, W. Lloyd Warner (1898-1970), que estava muito contrariado, pois tinha indicado Goffman para o departamento em Edimburgo, e, pouco tempo depois, ele foi para a ilha de Shetland: "O que agora ele apresenta, nem mesmo é um bom estudo da comunidade." Em resposta, Goffman cita a página oito da tese: "Este não é o estudo 'sobre' uma comunidade: é um estudo que ocorreu 'em' uma comunidade" (destaques de Goffman). O outro examinador, Everett C. Hughes (1897-1972), estranha o jargão utilizado como "euforia e disforia na interação" e considera o "capítulo de abertura da tese levemente irritante". Anselm L. Strauss (1916-1996) observava a arguição e "estava impressionado com a capacidade de Goffman de deixar que uma gota de suor escorresse pelo nariz enquanto ele se concentrava em responder a uma pergunta..." (Winkin, 1999, p.26, 27).

Ao longo dos anos, a tese receberia muitas análises. Destaco como relevante Fine, Manning e Smith (2000, p.XIX), que acentuam, com muita propriedade, que ela será fundamental na obra posterior de Goffman em três pontos: "Seu interesse na ordem de interação da vida cotidiana, sua preocupação com a etnografia e sociologia qualitativa, e seu estilo literário friamente irônico e autoconsciente são todos evidentes".

\section{Contexto e obra}

No esquema de Darnton, como assinalado, as relações e inter-relações que se estabelecem entre autor e editor são importantes, mas há uma dimensão que precede, em termos analíticos, essas relações. Alguns pontos foram traçados anteriormente, e outros são aqui retomados. The presentation of self in the everyday life pode ser visto como uma obra engendrada no interior do que seria conhecido como a "Segunda Escola de Chicago", formada a partir de 1945 e estendendo-se até 1960. Trazendo as tradições dos pesquisadores anteriores da Escola de Chicago, a marcada metodologia qualitativa de pesquisa será uma constante, assim como a expressão "interacionistas simbólicos", usada para situar teoricamente os componentes do grupo. Em entrevista de 1980 concedida a Verhoeven (1993, p.318), Goffman procurou se distanciar desse rótulo, respondendo: "Penso que sou tanto aquilo que você chama de interacionista simbólico quanto qualquer outra pessoa. Mas também sou um funcionalista estrutural no sentido tradicional; portanto, se não posso responder a essa pergunta, é porque não acredito que o rótulo signifique alguma coisa...". 
Referência especial deve ser feita aos trabalhos de Goffman anteriores a The presentation of self. Para Treviño (2003, p.8), "a sociologia de Goffman não era apenas o produto e registro de três épocas - 1950, 1960, 1970 -, ela também descrevia com precisão e, às vezes, até pressagiava as realidades interacionais de seus respectivos zeitgeist". Outras interpretações citadas por Treviño foram feitas, associando os primeiros trabalhos de Goffman - sobre fracasso (failure), constrangimento (embarrassment) e representação (self-presentation) "como um produto da era Eisenhower com sua paranoia da Guerra Fria, sociedade de massa, e o aumento do mal-estar social entre as classes médias urbanas".

Sem dúvida o ponto de partida dessa obra está no Prefácio, quando o próprio autor assinala: "Este trabalho serve como uma espécie de manual, que descreve detalhadamente uma perspectiva sociológica a partir da qual é possível estudar a vida social, principalmente aquela que é organizada dentro dos limites físicos de um prédio ou de uma fábrica" (Goffman, 1995, p.9).

Para ele, qualquer "estabelecimento social concreto" pode ser investigado. E esclarece que a perspectiva utilizada é a da representação teatral, com base nos princípios de caráter dramatúrgico.

No Capítulo I, Goffman (1995, p.29) aborda as representações (performances), que se referem "a toda atividade de um indivíduo que se passa num período caracterizado por sua presença contínua diante de um grupo particular de observadores e que tem sobre estes alguma influência". Ele denomina isso fachada (front) - "a parte do desempenho do indivíduo, que funciona regularmente de forma geral e fixa, com o fim de definir a situação para os que observam a representação". Antes, apresenta ao leitor algumas definições que são básicas para entender as relações indivíduo/representações (Goffman, 1995, p.23-24): interação, ou um encounter - "influência recíproca dos indivíduos sobre as ações uns dos outros, quando em presença física imediata"; um desempenho (performance) - "toda a atividade de um determinado participante, em dada ocasião, que sirva para influenciar, de algum modo, qualquer um dos outros participantes"; movimento (part) ou prática (routine) - "padrão de ação preestabelecido que se desenvolve durante a representação, que pode ser apresentado ou executado em outras ocasiões"; papel social (social role) - "promulgação de direitos e deveres ligados a uma determinada situação social".

O segundo momento importante nesse livro diz respeito às representações das equipes, quando analisa as dinâmicas grupais e a relação entre desempenho e plateia. Para o autor, "o conceito de equipe permite-nos conceber representações levadas a efeito por um ou mais de um ator" (Goffman, 1995, p.79). E sem dúvida a riqueza da elaboração do autor sobre esse conceito pode ser depreendida quando, quase ao final do capítulo, explica: "Uma equipe é um grupo, mas não um grupo em relação a uma estrutura ou organização social, e sim em relação a uma interação, ou série de interações, na qual é mantida a definição apropriada da situação" (p.99).

Goffman assinala nas conclusões que o indivíduo foi implicitamente dividido em dois papéis fundamentais: ator (performer) e personagem (character), sendo seus atributos de ordens diferentes, mas "ambos os conjuntos têm seu significado em termos do espetáculo que deve prosseguir" (Goffman, 1995, p.230-231). 


\section{Sobre a gênese dos conceitos}

Com a exposição anterior, a intenção foi fazer um apanhado dos conteúdos gerais do livro, mas algumas observações são necessárias para situar a gênese dos conceitos e mesmo da história pessoal do autor ao escolher, como assinala Freidson (1983, p.359), "o uso do vocabulário do palco" e a dramaturgia como metáfora para o estudo da interação face a face. Pode-se adiantar que o teatro se inscreve na tradição da família dele - "sua mãe costumava encenar peças amadoras, e sua irmã se profissionalizou como atriz, e o próprio Goffman participou, quando aluno do colegial, da encenação de Hamlet" (Shalin, 2014, p.4). Há registros fotográficos analisados por Cavan (2011, p.14-15) que mostram Erving e Florence fazendo poses como pequenos artistas.

Analisar os conceitos é falar do autor - da sua escrita, da noção de obra - "como princípio de agrupamento do discurso, como unidade e origem de suas significações, como foco de sua coerência", mas que também se materializa em textos e livros (Foucault, 1996, p.26).

A primeira edição do livro The presentation of self in everyday life é de 1956. Trata-se da edição publicada pela Universidade de Edimburgo, sob a forma de brochura, com 162 páginas. Não há referência à quantidade de exemplares impressos, e a publicação faz parte das monografias editadas pela universidade e traz na capa o preço - dez xelins. Atualmente, o preço dessa raridade atinge o valor de 2.500 dólares. Na entrevista concedida a Syme (2012, p.6), Shalin relata que "Erving deu à sua mãe a primeira edição de The presentation of self. Antes de sua mãe morrer, ela passou para sua prima, Esther Besbris, que doou o livro para o Arquivo Goffman... Não sei se a mãe de Erving leu o livro, mas tinha uma cópia".

Nessa edição, Goffman (1956) usa como epígrafe uma citação de George Santayana (18631952), repetida na edição de 1959, substituindo a epígrafe da tese, que citava Simmel. Da extensa citação, transcrevo o início: “Máscaras são expressões capturadas e ecos admiráveis de sentimento, ao mesmo tempo fiéis, discretas e excepcionais". Agradece ao Departamento de Antropologia Social da Universidade de Edimburgo, à Fundação Ford, na pessoa do professor Shils, aos mestres Hart, Warner, Hughes, aos colegas de Chicago, entre eles Elizabeth Bott e sua esposa - "Sem a colaboração da minha esposa, Angelica S. Goffman, este relato não teria sido escrito". Após o prefácio que ocupa uma página, elabora o sumário e a introdução com nove páginas; o sumário enuncia os seguintes capítulos: I - Performances, II - Teams, III - Regions and region behavior, IV - Discrepant roles, V - Communication out of character, VI - The arts of impression management, VII - Conclusion.

Smith (1999, p.2), em seu detalhado estudo dessa publicação, recupera resenhas feitas nas décadas de 1950 e 1960. A resenha de Stone (1957, p.105) sobre a edição de 1956 a considera "uma das contribuições mais importantes para a psicologia social nesta geração". Naegele (1956, p.632) afirma ser "uma peça brilhante, cujas riquezas precisam ser diretamente encontradas". Outras resenhas foram feitas, mas como anota Malufe (1992, p.40-42, 4661), que escreveu uma longa análise a respeito do papel das resenhas na obra de Goffman, deve-se considerar que existem diferenças entre "meras resenhas descritivas" e "resenhas críticas". Destaco apenas aquelas sobre The presentation, e ressalto que as resenhas citadas se incluem na segunda categoria, às quais Malufe acrescenta mais duas: Perry (1956) e 
Fallers (1962), pois discutem, analisam, criticam e situam a contribuição do trabalho para o campo do conhecimento a que se destina.

Em 1959, foi lançada a primeira edição norte-americana da obra. Foi publicada pela importante editora Doubleday (fundada em 1897), na série de brochuras, conhecida como Anchor Books (iniciada em 1953), que detém os direitos de publicação e tradução da obra. A cuidadosa edição, ampliada e revisada por Goffman - com 255 páginas, 261 referências e notas de rodapé, 186 autores citados, incluindo cinco referências do próprio Goffman - teve a capa desenhada por George Giusti (1908-1990), designer e arquiteto nascido em Milão (Itália), que emigrou para os EUA em 1939 e é considerado um dos mais importantes capistas da época. Para um livro cujo conteúdo era considerado anticonvencional como narrativa sociológica, nada mais oportuno do que uma capa desenhada por um artista "que evitou o clássico e procurou um efeito contemporâneo e até futurista. Ele foi bem-sucedido, uma vez que seus projetos estão consistentemente à frente de seu tempo" (ADC, 1979).

É importante esclarecer que o livro, segundo o próprio Goffman, traz material ilustrativo da tese, mas "neste estudo há matérias de naturezas diversas: ... respeitáveis pesquisas, ... narrativas informais ... frequente uso do meu estudo em uma comunidade nas ilhas Shetland" (Goffman, 1959, p.XI, XII).

Além disso, são incluídos observações e dados de outras pesquisas realizadas pelo autor com pacientes mentais (Goffman iniciou a pesquisa de campo no St. Elizabeths Hospital em Washington, em 1955, hospital psiquiátrico, com cerca de sete mil pacientes), e sobre questões de etiqueta, profissões, jogadores de cassinos, professores, estudantes de medicina etc. Goffman utiliza dissertações e teses defendidas na Universidade de Chicago e faz referências a filósofos (Sartre e Simone de Beauvoir), ao filósofo e teórico da literatura Kenneth Burke, a escritores (Kafka e Orwell) e sociólogos (Durkheim, Cooley, Mannheim, Simmel, Hughes, Warner, Strauss, Becker), entre outros.

As principais diferenças entre as três edições (1956, 1959 e 1971) são descritas por Smith (1989, p.447-455) em sua tese de doutorado, que aborda um paralelo entre Simmel e Goffman. De forma detalhada, Smith compara acréscimos de parágrafos, reformulações, transferência de notas de rodapé entre o texto de 1956 e as edições posteriores. Smith (1999, p.17, nota 4) retoma o tema e resume as principais diferenças entre as edições de 1956 e 1959:

Há (1) três novos parágrafos na Introdução (sobre a 'assimetria fundamental' do processo comunicativo); (2) seis novas páginas no final do Capítulo 1, 'Performances' (intitulado 'Reality and Contrivance'); (3) três novas páginas no final da Conclusão (intitulada 'Staging and the Self'). À primeira vista, parece que as diferenças entre as duas edições são meramente aditivas e estéticas - a segunda edição contém mais exemplos e deu ao autor a oportunidade de corrigir impropriedades menores. No entanto, Manning (1992, p.44-48) detecta uma sutil mudança analítica: as novas adições sugerem que o Goffman da segunda edição [1959] alcançou uma consciência mais clara do valor primariamente heurístico da metáfora dramatúrgica.

A "sutil mudança" apontada por Smith já havia sido assinalada por Philip Manning (1989, p.342), quando observou que a edição de 1959 tinha sido a oportunidade para Goffman "reconsiderar sua explicação sobre o self". Para Manning (1989, p.343), 
há duas caracterizações diferentes da pessoa em The presentation of self. A mais prevalente delas sugere que a pessoa é uma manipuladora por trás de uma variedade de máscaras públicas. Uma segunda pode ser discernida, no entanto, na qual a pessoa é retratada como um composto de múltiplos selves. A leitura cínica do texto é compatível apenas com a primeira dessas caracterizações. As revisões de Goffman questionam tanto a imagem do manipulador oculto quanto a utilidade das interpretações dramatúrgicas do mundo social.

Ao revisitar as primeiras resenhas dessa edição, registro mais detalhadamente a de Lloyd Fallers (1925-1974), sociólogo e antropólogo da Universidade de Chicago. Fallers (1962, p.191) aponta que "a análise de Goffman está repleta de conceitos úteis e é um estímulo para uma observação de campo mais perceptiva; a parte mais fraca deste livro é o último capítulo, no qual ele tenta, um tanto sem entusiasmo, relacionar sua estrutura de análise a outras [estruturas]". Para ele, "a utilidade da imagem dramatúrgica seria... grandemente reforçada por um esforço mais sistemático para relacioná-la aos conceitos que comumente usamos na análise mais macroscópica da sociedade e da cultura".

Giddens (2009, p.290) narra que, depois de cerca de vinte anos, releu a obra de Goffman e teve "algumas surpresas olhando para o livro". Para o sociólogo inglês, "Goffman usa o método antropológico, mas ele não está realmente atuando como antropólogo ... está mais preocupado com o cotidiano e o mundano do que com o exótico ... em descobrir divergências ou diferenças culturais ... seu território é universal" (p.290). Ressalto, desse trabalho, a importância atribuída por Giddens à noção de copresença (copresence) - "comportamento de indivíduos que ficam confinados por algum tempo" - e ao "gerenciamento de impressões" (impression management), no contexto de rituais cotidianos, realizados de forma colaborativa, que são a chave para a continuidade do self e a contenção ou regulação da emoção (Giddens, 2009, p.291-292).

A gênese dos conceitos tem sido um tema abordado por vários pesquisadores: Merrit (2018) cita o self social (social self), e Foucault (1996, p.39), as "sociedades de discurso".

\section{As traduções e o impacto do livro}

The presentation of self in everyday life foi traduzido em 17 idiomas (Gastaldo, 2008, p.150) e tornou-se "o maior best-seller da história da sociologia". A consagração oficial viria dois anos após sua primeira edição. Em 1961, o livro receberia o MacIver Award, da American Sociological Association, como livro excelente (outstanding book) de sociologia do ano. As primeiras traduções datam de 1969 (alemã e italiana) e da década de 1970 (francesa, japonesa, espanhola e brasileira).

A primeira edição da tradução brasileira do original de 1959 é de 1975, da Editora Vozes - A representação do eu na vida cotidiana -, que até o momento publicou vinte edições. Segundo informa a editora,

anteriormente o sistema não contemplava as reimpressões, embora elas fossem feitas. Dos últimos anos para cá, estamos fazendo reedição somente quando há atualização do conteúdo, fora isso, fazemos reimpressão da última edição. Nesse caso, tivemos cinco reimpressões da $20^{\mathrm{a}}$ edição, totalizando 31.697 exemplares impressos (Soares, 16 maio 2019). 
"Considero o título que o livro ganhou em português - A representação do eu na vida cotidiana - uma má tradução: presentation é 'apresentação', e não 'representação'; selfé um conceito central na teoria sociológica de Chicago, e, além da difícil tradução, é normalmente utilizado no original" (Carlin, 2004a, p.160). Ao analisar a importância do livro, Smith (1989, p.446) apresenta um levantamento das citações de 11 livros de Goffman no período de 1971 a 1985. Ocupam os três primeiros lugares: The presentation of self (1.419 citações), Stigma (1.059), e Asylums (1.018).

Atualizei o período de citações, de 1980 a maio de 2019, e a classificação das cinco obras mais citadas de Goffman no Google Scholar (2019) mostrou o seguinte: The presentation of self in everyday life (59.134 citações); Stigma (32.694); Frame analysis (30.802); Interaction ritual (26.552); e Asylums (14.597).

Ao estudar Simmel e Goffman e analisar a relação entre citações e "influência", Smith $(1989$, p.215, 216) faz uma observação que aplico em relação ao número de citações das obras de Goffman: "Citações não são um guia confiável para influências relevantes... No entanto, as informações fornecem 'orientação inicial útil' e têm a utilidade de tornar a noção notoriamente escorregadia de 'influência' em termos empíricos” (destaques meus). Ou seja, a referência numérica neste estudo sobre o livro de Goffman pode ser um bom ponto de partida para uma análise amostral da qualidade dos textos e da influência sobre diversos autores.

\section{Considerações finais}

É inegável a importância e a influência exercida por Goffman após 60 anos da publicação do seu emblemático livro The presentation of self in everyday life. A consagração pela academia é fato constatado. Há cerca de 20 anos, em 1998, o tema do $14^{\circ}$ ISA World Congress of Sociology, realizado em Montreal, Canadá, foi "The Future of Sociology and the Social Sciences in the 21st Century". A fim de avaliar criticamente a herança sociológica do século XX, em 1997, a International Sociological Association (ISA) realizou uma pesquisa de opinião entre seus membros com o objetivo de listar os livros publicados no século XX de maior influência em seus trabalhos como sociólogos; 16\% dos integrantes (455 de 2.785) participaram da pesquisa. The presentation of self in everyday life aparece em décimo lugar (ISA, s.d.).

As análises feitas sobre o livro são inúmeras, e diversos são os temas abordados, situandoos em distintos campos do conhecimento, como educação, psicologia social, sociologia, antropologia, política, criminologia, comunicação, comunicação mediada, sociolinguística, etnografia e sociologia da saúde e do adoecimento (em The presentation of self, constatei 27 referências e notas sobre medicina, relação médico/paciente, estudantes de medicina e outras profissões da saúde). Essa prolixidade de campos e temas científicos no uso das obras de Goffman é derivada diretamente de seu legado como pesquisador, muitas vezes denominado cornucópia metafórica decorrente de uma cornucópia conceitual. Essas expressões aparecem em diversos textos que tratam da obra de Goffman, especialmente em Collins (citado em Jacobsen, 2010, p.23), Williams (1983, p.101), Manning (1992, p.54) e Jacobsen (2010). De modo geral, os analistas apontam que o uso de metáforas contribuiu para a geração, o desenvolvimento e a elaboração dos conceitos goffmanianos. 
Segundo Smith (1989, p.149), comenta-se muitas vezes que os "escritos sociológicos" parecem "um pouco disformes e desordenados", mas, segundo o sociólogo, que se tornou especialista em Goffman, "é possível reconstruir um modelo unificado de interação do trabalho de Goffman". Nessa direção, cita Birrell (1978), que realizou pesquisa exemplar desse modelo. Smith (1989, p.149-153) relata que "Birrell vasculhou os escritos de Goffman a fim de encontrar cada um dos conceitos existentes. Cada termo e sua definição foram digitados em um cartão $6 \times 4$, e a pesquisa revelou uma população de conceitos cuja numeração é superior a $900 \ldots$ Os cartões foram então copiados e ordenados em um arranjo lógico". Verificou-se que "o produto do processo da construção [desse] modelo se assemelhava a um jogo desenfreado de paciência".

Outros pesquisadores acercaram-se da produção de Goffman levantando numericamente os conceitos e neologismos que ele criou. Para Jacobsen e Kristiansen (2015, p.181), “Goffman tinha um dom especial para cunhar muitos conceitos que agora são itens corriqueiros [households itens] em sociologia e disciplinas relacionadas". Citam, como exemplo, o trabalho de Randall Collins, do inicio da década de 1980, que, como verifiquei, menciona cerca de cinquenta dos mais importantes conceitos criados por Goffman, mas, como visto anteriormente, esse número é bem maior (citado em Jacobsen, Kristiansen, 2015, p.182).

Assim, a literatura acadêmica tem mostrado que Goffman continua estimulando e desafiando os pesquisadores num debate permanente de suas contribuições. Sem dúvida, uma discussão que sempre é lembrada refere-se à teorização na obra de Goffman, e em especial em The presentation of self. Freidson (1983, p.361) foi bastante enfático ao dizer:

Acredito que o trabalho de Goffman vive e viverá não como uma contribuição para o desenvolvimento da teoria sociológica sistemática, mas sim como uma contribuição para a consciência humana ... Considerar Goffman uma fonte de teoria abstrata e sistemática é falso para a substância e o espírito de seu trabalho... Conceitos, sim, mas não teorias, e mesmo no caso de conceitos, que sejam provisórios, excluídos quando seu propósito imediato for cumprido.

Não somente o mundo acadêmico está presente nesse empreendimento de manter viva a contribuição de Goffman. Há outros seguidores. Deixaram de lado a recomendação do final do texto do sociólogo canadense, quando escreve: "A alegação de que todo o mundo é um palco... não deve ser levada muito a sério" (Goffman, 1959, p.254) - e 70 anos depois de sua pesquisa em Unst, Goffman volta, literalmente, a Baltasound, atestando que a "metáfora da vida como teatro é rica de significados" (Kivisto, Pittman, 2013, p.298). Em outubro de 2018, um elenco de jovens de Shetland e uma companhia de teatro do Canadá aplicaram os insights de Goffman no projeto denominado "The World is a Wedding, the Presentation of Unst in Everday Life" - "a apresentação de Unst no cotidiano, um show imersivo sobre conexão, união e como vivemos uns com os outros" (National Theatre of Scotland, 2018).

\section{AGRADECIMENTOS}

Agradeço à Verônica Maria Guedes Soares, assistente editorial da Editora Vozes, as informações prestadas, e ao revisor as oportunas sugestões.

Essa pesquisa teve financiamento do Ministério da Ciência, Tecnologia e Inovação e do Conselho Nacional de Desenvolvimento Científico e Tecnológico (processo 303924/2019-5). 
${ }^{1}$ Nessa e nas demais citações de textos em inglês, a tradução é livre.

\section{REFERÊNCIAS}

ADAMS, Thomas R.; BARKER, Nicholas. A new model for the study of the book. In: Barker, Nicholas (ed.). A potencie of life: books in society: the Clark Lectures, 1986-1987. London: British Library/Oak Knoll Press, 1993. p.5-43.

ADC, Associated Designers of Canada. George Giusti, 1979. Disponível em: http://adcglobal. org/hall-of-fame/george-giusti. Acesso em: 5 maio 2019.

BIRRELL, Susan Jane. Sporting Encounters: An examination of the work of Erving Goffman and its application to sport. Tese (Doutorado) University of Massachusetts, Amherst, 1978.

CARLIN, Andrew P. "Enquadrando" bibliografias - reflexividade, relevância e a "imaginação sociológica". In: Gastaldo, Édison (org.). Erving Goffman: desbravador do cotidiano. Porto Alegre: Tomo Editorial, 2004a. p.147-166.

CARLIN, Andrew P. Erving Goffman: obras originais e traduções. In: Gastaldo, Édison (org.). Erving Goffman: desbravador do cotidiano. Porto Alegre: Tomo Editorial, 2004b. p.167-172.

CAVAN, Sherri. When Erving Goffman was a boy. In: Shalin, Dmitri N. Bios Sociologicus: The Erving Goffman Archives, 2011. p.1-34. Disponível em: https://digitalscholarship.unlv. edu/goffman_archives/89. Acesso em: 5 dez. 2019.

DARNTON, Robert. "What is the history of books?" revisited. Modern Intellectual History, v.4, n.3, p.495-508, 2007.

DARNTON, Robert. What is the history of books? Daedalus, v.111, n.3, p.65-83, 1982. Disponível em: http://nrs.harvard.edu/urn3:HUL.InstRepos:3403038. Acesso em: 15 jan. 2018.

FALLERS, Lloyd. Review - The presentation of self in everyday life. American Anthropologist, v.64, n.1, p.190-191, 1962.

FINE, Alan Gary; MANNING, Philip; SMITH, Gregory W.H. Introduction. In: Fine, Alan Gary; Smith, Gregory W.H. (ed.). Erving Goffman. v.1. London: Thousand Oaks; New Delhi: Sage Publications, 2000. p.IX-XLIV.

FINE, Alan Gary; SMITH, Gregory W.H. (ed.). Erving Goffman. London: Thousand Oaks; New Delhi: Sage Publications, 2000.
FOUCAULT, Michel. A ordem do discurso. São Paulo: Loyola, 1996.

FREIDSON, Eliot. Celebrating Erving Goffman. Contemporary Sociology, v.12, n.4, p.359-362, 1983.

GASTALDO, Édison. Goffman e as relações de poder na vida cotidiana. Revista Brasileira de Ciências Sociais, v.23, n.68, p.149-153, 2008.

GIDDENS, Anthony. On rereading The Presentation of Self: some reflections. Social Psychology Quarterly, v.72, n.4, p.290-295, 2009.

GOFFMAN, Erving. A representação do eu na vida cotidiana. Petrópolis: Editora Vozes, 1995.

GOFFMAN, Erving. The interaction order. American Sociological Review, v.48, n.1, p.1-17, 1983.

GOFFMAN, Erving. The insanity place. Psychiatry, v.32, n.4, p.357-388, 1969.

GOFFMAN, Erving. The presentation of self in everyday life. Garden City: Doubleday, Anchor Books, 1959.

GOFFMAN, Erving. The presentation of self in everyday life. Edinburgh University of Edinburgh: Social Sciences Research Centre, 1956. Disponível em: http://cdclv.unlv.edu/ega. Acesso em: 12 jun. 2018.

GOFFMAN, Erving. Communication conduct in an island community. Tese (Doutorado em Sociologia) - The University of Chicago, Chicago, 1953.

GOOGLE SCHOLAR. Erving Goffman citations, 2019. Disponível em: https://scholar.google. com/citations?user=rahhbn0AAAAJ\&hl=en. Acesso em: 2 jun. 2019.

ISA, International Sociological Association. History of ISA. Books of the XX Century, s.d. Disponível em: https://www.isa-sociology.org/ en/about-isa/history-of-isa/books-of-the-Xxcentury. Acesso em: 2 jun. 2019.

JACOBSEN, Michael Hviid (ed.). The contemporary Goffman. New York: Routledge, 2010.

JACOBSEN, Michael Hviid; KRISTIANSEN, Soren. The social thought of Erving Goffman. Thousand Oaks: Sage Publications, 2015. 
KIVISTO, Peter; PITMAN, Dan. Goffman's dramaturgical sociology personal sales and service in a commodified world. In: Kivisto, Peter (ed.). Illuminating social life: classical and contemporary theory revisited. Thousand Oaks: Sage Publications, 2013. p.297-318.

MALUFE, José Roberto. A retórica da ciência: uma leitura de Goffman. São Paulo: Educ, 1992.

MANNING, Philip. Erving Goffman. In: Ritzer, George (ed.). The Blackwell Companion to Major Contemporary Social Theorists. Thousand Oaks: Sage Publications, 2005. p.334-339.

MANNING, Philip. Erving Goffman and modern sociology. Stanford: Stanford University Press, 1992.

MANNING, Philip. Goffman Revisions. Philosophy of the Social Sciences, v.19, n.3, p.341-343, 1989. Disponível em: dhttps:// engagedscholarship.csuohio.edu/clsoc_crim_ facpub. Acesso em: 2 jun. 2019.

MERRITT, Marilyn. An interdisciplinary anthropologist at work: a focused intellectual biography of Erving Goffman. In: Bérose: Encyclopédie Internationale des Histoires de L'anthropologie. Paris: [s.n.], 2018. p.115. Disponível em: http://www.berose.fr/ article1278.html?lang=fr. Acesso em: $12 \mathrm{dez}$. 2019.

NAEGELE, Kaspar D. Review: The Presentation of Self in Everyday Life. American Sociological Review, v.21, n.5, p.631-632, 1956.

NATIONAL THEATRE OF SCOTLAND. The World is a Wedding, the Presentation of Unst in Everyday Life, 2018. Disponível em: https:// www.nationaltheatrescotland.com/production/ presentation-of-unst. Acesso em: 15 dez. 2018.

OLIVEIRA, M.M. Pesquisa documental e bibliográfica, 2009. Disponível em: https://www. passeidireto.com/arquivo/74036428/pesquisadocumental-e-bibliografica. Acesso em: 28 maio 2021.

PERRY, Helen S. Review: The presentation of self in everyday life. Psychiatry, v.19, n.2, p.209-211, 1956.

SHALIN, Dmitri N. Interfacing biography, theory and history: the case of Erving Goffman. Symbolic Interaction, v.37, n.1, p.2-40, 2014.
SHALIN, Dmitri N. Introduction. In: Shalin, Dmitri N. Bios Sociologicus: The Erving Goffman Archives, 2009, p.1-4. Disponível em: https:// digitalscholarship.unlv.edu/goffman_archives/1. Acesso em: 12 jun. 2018.

SIMMEL, Georg. The sociology of Georg Simmel. Illinois: The Free Press, c.1950.

SMITH, Greg. Erving Goffman. New York: Routledge, 2006.

SMITH, Greg. Introduction: Interpreting Goffman's legacy. In: Smith, Greg (ed.). Goffman and social organization studies in a sociological legacy. New York: Routledge, 1999. p.1-18.

SMITH, Gregory William Hanson. A Simmelian reading of Goffman. Tese (Doutorado) University of Salford, Manchester, England, 1989.

SOARES, Verônica Maria Guedes. Número de exemplares de A representação do Eu na Vida Cotidiana. Destinatário: Everardo Duarte Nunes. [S.1.], 16 maio 2019. Mensagem eletrônica.

STONE, Gregory P. Review: The presentation of self in everyday life. American Journal of Sociology, v.62, n.1, p.105, 1957.

SYME, S. Leonard. Dmitri Shalin Interview with S. Leonard Syme about Erving Goffman. In: Shalin, Dmitri N. (ed.). Bios Sociologicus: The Erving Goffman Archives, 2012. p.1-15. Disponível em: https://digitalscholarship.unlv.edu/goffman archives/68. Acesso em: 15 dez. 2018.

TREVIÑO, A. Javier. Introduction: Erving Goffman and the interaction orden. In: Treviño, A. Javier (org.). Goffman's legacy. New York: Rowman \& Littlefield, 2003. p.1-49.

VERHOEVEN, Jef C. An interview with Erving Goffman, 1980. Research on Language and Social Interaction, v.26, n.3, p.317-348, 1993.

WILLIAMS, Robin. Erving Goffman: an appreciation: sociological tropes, a tribute to Erving Goffman. Theory, Cultures and Society, v.2, n.1, p.99-102, 1983.

WINKIN, Yves. Erving Goffman: What is a life? The uneasy making of intellectual biography. In: Smith, Greg (ed.). Goffman and Social Organization Studies in Sociological Legacy. London: Routledge, 1999. p.19-41.

WINKIN, Yves. Goffman à Baltasound. Politix, v.1, n.3-4, p.66-70, 1988.

\section{$\rightarrow \rightarrow \rightarrow<<<$}

